\title{
Statistical Analysis of the Dynamic Performance of Reinforcement Steel at Elevated Temperatures: The Case of Johnson-Cook Model
}

\author{
Egidijus Rytas VAIDOGAS \\ Vilnius Gediminas Technical University, Sauletekioal.11,10223Vilnius, Lithuania, E-mail: egidijus.vaidogas@vgtu.lt \\ crossref http://dx.doi.org/10.5755/j02.mech.30350
}

\section{Introduction}

In situations of industrial accidents, military assaults and terrorist events, reinforced concrete components of building structures and elements of critical infrastructure can be exposed to a combined action of explosive loads and fire. Fires can not only act on structures but also trigger off explosions. A combined dynamic and thermal action on reinforced concrete structures is assessed by a coupled modelling of strain rate sensitive material properties and strength deterioration due to fire loading [1-3]. As for reinforcing bars, constitutive laws of steel are used to consider both strain rate sensitivity and thermal softening. The practice of the coupled modelling of stress-strain relation of reinforcement bars is prevailed by the constitutive law known as the Johnson-Cook (JC) model $[4,5]$. This model has been developed to consider the strain and strain rate hardening part of stress-strain relation and includes a component (singleparameter sub-model) accounting for thermal softening of steel.

The problem considered in the present study arises from the fact that the original version of JC model from the 1980 s and its subsequent modifications are purely deterministic [4-6]. In a series of studies, the deterministic JC model and several models of similar nature are fitted to experimental data as functions of strain rate and elevated temperature with fixed parameters called the material constants. An application of the deterministic models contradicts to an obvious statistical variability of experimental data expressed by strain-stress records. The present study seeks to examine the above contradiction by a closer look at the JC model from statistical point of view and to suggest recipes for alleviating this contradiction. It is proposed how to fit components of the JC model by applying repetitive data that consists of a relatively small number of stress-strain records.

\section{A brief literature review}

Concrete and steel of reinforced concrete structures may be exposed to dynamic loadings at a wide range of strain rates $\dot{\varepsilon}$. They range from the order of $10^{-7} \ldots 10^{-8} \mathrm{~s}^{-1}$ for quasi-static loading to the order $10^{2} \ldots 10^{3} \mathrm{~s}^{-1}$ for hard impacts and blast [7]. The pair of the dynamic rate $\dot{\varepsilon}$ and the static rate $\dot{\varepsilon}_{s}$ is the key information for quantifying an improvement in mechanical properties of steel (strength, modulus of elasticity, energy absorption). The improvement is expressed by dynamic increase factors (DIFs). In this study, these factors will be denoted by the symbol $D I F_{I}(\dot{\varepsilon})$ [8]. $D I F$ is a ratio of material property $\Pi$ at a dynamic strain rate $\dot{\varepsilon}$ to property at quasi-static strain rate $\dot{\varepsilon}_{s}$, namely, the ratio of $\Pi(\dot{\varepsilon})$ to $\Pi\left(\dot{\varepsilon}_{s}\right)$.
Most of the research devoted to the strain rate sensitivity of structural steel properties $\Pi$ is related to the yield stress $\sigma_{y}(\dot{\varepsilon})$. Due to the importance of $\sigma_{y}(\dot{\varepsilon})$ to the design of dynamically loaded reinforced concrete structures and in the interests of brevity, the present study will be limited by the dynamic yield stress of structural steels. Often cited examples of the factor $D I F_{\sigma_{y}}$ related to reinforcement steel and expressed by the static to dynamic yield stress ratio $\sigma_{y d}(\dot{\varepsilon}) / \sigma_{y s}\left(\dot{\varepsilon}_{s}\right)$ are given by [9]:

$$
D I F_{\sigma_{y}}\left(\dot{\varepsilon}, \dot{\varepsilon}_{s}\right)=\lambda \log _{10}\left\{\dot{\varepsilon} / \dot{\varepsilon}_{s}\right\}
$$

with the static stress $\dot{\varepsilon}_{s}=10^{-2} \mathrm{~s}^{-1}$ and

$$
D I F_{\sigma_{y}}\left(\dot{\varepsilon}, \dot{\varepsilon}_{s}\right)=1+\left(6.0 / \sigma_{y s}\left(\dot{\varepsilon}_{s}\right)\right) \ln \left\{\dot{\varepsilon} / \dot{\varepsilon}_{s}\right\}
$$

with the static stress $\dot{\varepsilon}_{s}=5 \times 10^{-5} \mathrm{~s}^{-1}$, where: $\lambda$ is equal to 0.03 for the strain range $\varepsilon=0.02-0.03$.

The models $\sigma_{y d}(\dot{\varepsilon})$ are usually called the constitutive equations. The equations with the single argument $\dot{\varepsilon}_{s}$ do not consider the influence of temperature of specimens and in-situ reinforcement bars subjected to dynamic loading. It is simply assumed that this temperature is equal to the temperature of the room, $T_{\text {room }}$, in which dynamic tests are carried out (normal or room temperature). A review of various temperature-insensitive models $\sigma_{y d}(\dot{\varepsilon})$ are presented, for instance, by Al Salahi and Othman [10] and Scholl et al. [11].

The function $\sigma_{y d}(\cdot)$ has been also developed to consider elevated temperatures of steel specimens. The yield stress $\sigma_{y d}(\cdot)$ is expressed as a function of absolute temperature of the specimen $T$, or dimensionless (homologous) temperature $T_{h}$ given by the ratio:

$$
T_{h}=\left\{\begin{array}{ll}
0 & \text { if } T \leq T_{r} \\
\left(T-T_{r}\right) /\left(T_{\text {melt }}-T_{r}\right) & \text { if } T_{r}<T<T_{\text {melt }}, \\
1 & \text { if } T \geq T_{\text {melt }}
\end{array},\right.
$$

where: $T_{\text {melt }}$ is the melting temperature of the specimen and $T_{r}$ is the reference temperature that is usually taken equal to the room temperature $T_{\text {room }}$.

H. Qian et al. [13], suggested to model the coupled influence of strain rate and temperature by introducing two separate DIFs:

$$
\sigma_{y d}(\dot{\varepsilon}, T) / \sigma_{y s}\left(\dot{\varepsilon}_{s}\right)=\gamma_{\sigma_{y}}(\dot{\varepsilon}) \gamma_{\sigma_{y}}(T),
$$


where: $\gamma_{\sigma_{y}}(\dot{\varepsilon})$ and $\gamma_{\sigma_{v}}(T)$ are factors expressing the influence of strain rate and high temperature, respectively. How- ever, the prevailing approach is to use the constitutive equations, the arguments of which include both variables $\dot{\varepsilon}$ and $T$. Four examples of such equations are given in Table 1 .

Table 1

Constitutive equations $\sigma_{y d}(\dot{\varepsilon}, T)$ expressing the sensitivity of steel to stress to stain rate and high temperatures

\begin{tabular}{|c|c|}
\hline Name of model & Eyring model [12] \\
\hline Constitutive equation & $\sigma_{y d}(\dot{\varepsilon}, T)=c_{1} T\left(\ln \left\{2 c_{2} \dot{\varepsilon}\right\}+E_{\alpha} / R T\right)$ \\
\hline \multicolumn{2}{|c|}{$\begin{array}{l}\text { Comments: } c_{1} \text { and } c_{2} \text { are two material parameters of the Eyring model; } E_{\alpha} \text { is the activation energy of the } \alpha \text {-relaxation; } R \text { is the } \\
\text { universal gas constant; } T \text { is the absolute temperature of the specimen. In the Eyring model, the yield stress } \sigma_{y}(\dot{\varepsilon}, T) \text { is a linear } \\
\text { function of the strain rate logarithm } \ln \left\{2 c_{2} \dot{\varepsilon}\right\} \text {. This linearity exists only up to some limiting value of } \dot{\varepsilon} \text { and the strain rate sensi- } \\
\text { tivity increases at high strain rate [10] }\end{array}$} \\
\hline Name of model & Ree-Eyring model [12] \\
\hline Constitutive equation & $\sigma_{y d}(\dot{\varepsilon}, T)=c_{1} T\left(\ln \left\{2 c_{2} \dot{\varepsilon}\right\}+E_{\alpha} / R T\right)+c_{3} T \sinh ^{-1}\left\{c_{2} \dot{\varepsilon} \exp \left\{E_{\beta} / R T\right\}\right\}$ \\
\hline \multicolumn{2}{|c|}{$\begin{array}{l}\text { Comments: } c_{1}, c_{2}, c_{3} \text { and } c_{4} \text { are four material constants of the Ree-Eyring model; } E_{\beta} \text { is the activation energy of the } \beta \text {-relaxation. } \\
\text { The Ree-Eyring model assumes two relaxation processes and considers the increase of the strain rate sensitivity at high strain rate } \\
{[10] \text {. }}\end{array}$} \\
\hline Name of model & Johnson-Cook (JC) model $[4,5]$ \\
\hline Constitutive equation & $\sigma_{J C}(\dot{\varepsilon}, T)=\left(c_{1}+c_{2} \varepsilon_{p}^{c_{3}}\right)\left(1+c_{4} \ln \left\{\dot{\varepsilon} / \dot{\varepsilon}_{0}\right\}\right)\left(1-T_{h}^{c_{5}}\right)$ \\
\hline \multicolumn{2}{|c|}{$\begin{array}{l}\text { Comments: } \varepsilon_{p} \text { is the true (equivalent) plastic strain; } c_{1}, c_{2}, \ldots, c_{5} \text { are five material parameters of the Johnson-Cook model; } \dot{\varepsilon}_{0} \text { is } \\
\left.\text { the reference quasi-static strain rate commented in Sec. } 3.2 \text { and } T_{h} \text { is the homologous (dimensionless) temperature (Eq. ( }(3)\right) \text {. The } \\
\text { parameters } c_{1}, c_{2}, c_{3} \text { and } c_{4} \text { have to be determined from experimental results. The parameter } c_{1} \text { is the quasi-static yield stress. The } \\
\text { parameters } c_{2} \text { and } c_{3} \text { describe the response to strain hardening. The parameter } c_{4} \text { represents the strain rate sensitivity. The parame- } \\
\text { ter } c_{5} \text { models the thermal softening. }\end{array}$} \\
\hline Name of model & Huh-Kang model [6] \\
\hline Constitutive equation & $\sigma_{y d}(\dot{\varepsilon}, T)=\left(c_{1}+c_{2} \varepsilon^{c_{3}}\right)\left(1+c_{4} \ln \left\{\dot{\varepsilon} \mid \dot{\varepsilon}_{0}\right\}+c_{6}\left(\ln \left\{\dot{\varepsilon} / \dot{\varepsilon}_{0}\right\}\right)^{2}\right)\left(1-T_{h}^{c_{5}}\right)$ \\
\hline
\end{tabular}

The models $\sigma_{y d}(\dot{\varepsilon})$ and $\sigma_{y d}(\dot{\varepsilon}, T)$ has been developed over the past 80 years. New models are still suggested or improved in the present time $[11,14,15]$. Research on metals simultaneously subjected to large strains and high temperatures began in 1940s [14]. However, the response of reinforcement bars to high strain-rate and elevated temperatures has been investigated mainly in the previous two decades $[1-3,16]$. The general conclusion of this investigation is that the higher is the temperature, the larger is the strain rate effect.

Despite relatively large quantity of experimental results obtained by investigating the combined effect of high temperature exposure and strain rate on reinforcement bars, the only constitutive equation $\sigma_{y d}(\dot{\varepsilon}, T)$ suggested by various authors until the present time was the Johnson-Cook model presented in Table 1. The Huh-Kang model developed by modifying Johnson-Cook model was not applied to reinforcement steel [6].

The Eyring model and its extension called the ReeEyring model were not developed specifically for reinforcement bars and later were not applied to this kind of steel [12]. In addition, these models require to assess the relaxation activation energies $E_{\alpha}$ and $E_{\beta}$, and therefore the implementation of these models is less practical when compared to the Johnson-Cook model.

The preceding assessment of the temperature-sensitive models $\sigma_{y d}(\dot{\varepsilon}, T)$ described in Table 1 leaves little choice but to look at the problem of strain rate sensitivity of reinforcement steel exposed to elevated temperatures in the light of the constitutive Johnson-Cook model.

\section{A closer look at the Johnson-Cook model}

\subsection{Multiplicative composition and sensitivity analysis}

The JC presented in Table 1 considers strain hardening, strain rate sensitivity and thermal softening. The lefthand side of this model is the true stress $\sigma_{J C}$ that can be interpreted as the function of three arguments partially explained in Table 1:

$$
\sigma_{J C}\left(\varepsilon_{p}, \dot{\varepsilon}^{\prime}, T_{h}\right)=\left(c_{1}+c_{2} \varepsilon_{p}^{c_{3}}\right)\left(1+c_{4} \ln \dot{\varepsilon}^{\prime}\right)\left(1-T_{h}^{c_{5}}\right) .
$$

The argument $\varepsilon_{p}$ of $\sigma_{J C}\left(\varepsilon_{p}, \dot{\varepsilon}^{\prime}, T\right)$ is the true plastic strain called also the equivalent or logarithmic plastic strain and $\dot{\varepsilon}^{\prime}$ is the dimensionless plastic strain rate given by the ratio $\dot{\varepsilon} / \dot{\varepsilon}_{0}$. The denominator $\dot{\varepsilon}_{0}$ is assumed in a number of studies as the quasi-static strain rate $\dot{\varepsilon}_{s}$ with varying values $0.00025 \mathrm{~s}^{-1}, 0.001 \mathrm{~s}^{-1}, 0.002 \mathrm{~s}^{-1}$ or $0.0025 \mathrm{~s}^{-1}[1$, $14,17]$. However, normally $\dot{\varepsilon}_{0}$ is taken as $1.0 \mathrm{~s}^{-1}$ and this value is called the reference quasi-static strain rate [1]. The choice $\dot{\varepsilon}_{0}=1.0 \mathrm{~s}^{-1}$ means that the JC model will be applicable to relatively large strain rates $\dot{\varepsilon}$ exceeding $1.0 \mathrm{~s}^{-1}$ and belonging to strain rate ranges related to hard impact and 
blast (Fig. 1). If the quasi-static stress is determined for the value the ratio $\dot{\varepsilon}^{\prime}<1.0$, the JC model can be adjusted for $\dot{\varepsilon}^{\prime}=1.0$ by increasing the quasi-static values of the constants $c_{1}$ and $c_{2}$ by the ratio of the stresses at $\dot{\varepsilon}^{\prime}=1.0$ and $\dot{\varepsilon}^{\prime}<1.0[5]$.

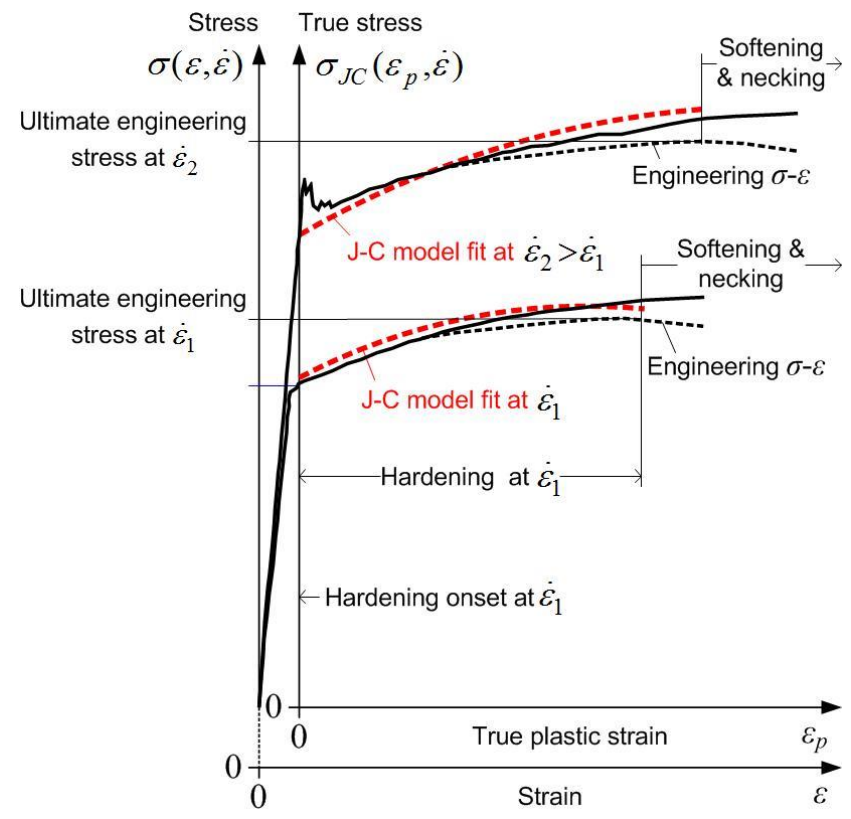

Fig. 1 A schematic depiction of the JC model and experimental records

The right-hand side of the JC model is a product of three factors that consider three different effects. The factor $\left(c_{1}+c_{2} \varepsilon_{p}^{c_{3}}\right)$ considers the isotropic hardening of steel and represents the quasi-static flow. This factor can be regarded as the model for the quasi-static stress-strain curve [14]. The parameter $c_{1}$ can be the yield stress of hot rolled steels or the stress corresponding to $0.2 \%$ offset strain of cold drawn steels. For simplicity, the parameter $c_{1}$ will express either of the stresses. The magnification factor $\left(1+c_{4} l n \dot{\varepsilon}^{\prime}\right)$ represents the strain rate effect on the stress. The factor $\left(1-T_{h}^{c_{5}}\right)$ expresses the temperature effect.

The product $\left(c_{1}+c_{2} \varepsilon_{p}^{c_{3}}\right)\left(1+c_{4} \ln \dot{\varepsilon}^{\prime}\right)$ means that the difference between dynamic and static stress at the same strain increases with increasing strain rate. The expression $\left(c_{1}+c_{2} \varepsilon_{p}^{c_{3}}\right)$ does not allow to describe a yield plateau and so JC models is suited only for strain-hardening stage (Fig. 1).

In JC, strain hardening, strain rate hardening and thermal softening are considered in a decoupled multiplication form. This allows to evaluate the parameters $c_{1}, \ldots, c_{5}$ in tests of at least four kinds:

- quasi-static test at room the temperature $T_{r}=T_{\text {room }}$;

- quasi-static test at elevated temperatures $T>T_{\text {room }}$ $\left(T_{h}>0\right)$

- dynamic test at room temperature $T=T_{\text {room }}$;

- dynamic tests at elevated temperatures $T>T_{\text {room }}$.

These tests are independent of each other, except that they must be carried out using the same sort of metal and, wherever possible, the same testing equipment and measuring procedures.

Table 2

Parameter values of the JC model related to the reinforcement steels B500A and B500B presented by Cadoni and Forni [1] as well as variation ranges of these parameters used for the global sensitivity analysis

\begin{tabular}{|c|c|c|c|c|c|}
\hline \multirow{2}{*}{$\begin{array}{l}\text { The name of argument or model pa- } \\
\text { rameter }\end{array}$} & \multirow{2}{*}{$\begin{array}{l}\text { Sym- } \\
\text { bol }\end{array}$} & \multirow{2}{*}{$\begin{array}{l}\text { Value(s) obtained for } \\
\text { B500A steel }\end{array}$} & \multirow{2}{*}{$\begin{array}{l}\text { Value(s) obtained for } \\
\text { B500B steel }\end{array}$} & \multicolumn{2}{|c|}{$\begin{array}{l} \pm 20 \% \text { variation ranges used for the } \\
\text { sensitivity analysis }\end{array}$} \\
\hline & & & & B500A & B500B \\
\hline Yield stress, $\mathrm{MPa}$ & $c_{1}$ & 564 & 571 & {$[451,677]$} & {$[457,685]$} \\
\hline $\begin{array}{l}\text { The first parameter of strain harden- } \\
\text { ing, MPa }\end{array}$ & $c_{2}$ & 946 & 643 & {$[757,1135]$} & {$[514,772]$} \\
\hline $\begin{array}{l}\text { The second parameter of strain hard- } \\
\text { ening, - }\end{array}$ & $c_{3}$ & 0.875 & 0.720 & {$[0.700,1.050]$} & {$[0.576,0.864]$} \\
\hline The strain rate sensitivity parameter, - & $c_{3}$ & 0.01726 & 0.02143 & {$[0.01381,0.0207]$} & {$[0.01714,0.0257]$} \\
\hline $\begin{array}{l}\text { Thermal parameter, - } \\
\text { (for temperature ranges } 200^{\circ} \mathrm{C}- \\
600^{\circ} \mathrm{C} \text { and true strain rate } 200 \mathrm{~s}^{-1}- \\
1000 \mathrm{~s}^{-1} \text { ) }\end{array}$ & $c_{4}$ & $\begin{array}{c}0.859-0.977 \text { with the } \\
\text { value } 0.907^{(1)} \text { at } 450 \mathrm{~s}^{-} \\
1-600 \mathrm{~s}^{-1}\end{array}$ & N/A & {$[0.726,1.088]$} & N/A \\
\hline $\begin{array}{l}\text { Thermal parameter, }- \\
\text { (for temperature ranges } 200^{\circ} \mathrm{C}- \\
600^{\circ} \mathrm{C} \text { and true strain rate } 250 \mathrm{~s}^{-1}- \\
800 \mathrm{~s}^{-1} \text { ) }\end{array}$ & $c_{5}$ & N/A & $\begin{array}{c}0.919-1.353 \text { with the } \\
\text { value } 1.180 \text { at } 600^{\circ} \mathrm{C} \text { and } \\
600 \mathrm{~s}^{-1}\end{array}$ & N/A & {$[0.944,1.416]$} \\
\hline Melting temperature, ${ }^{\circ} \mathrm{C}$ & $T_{\text {melt }}$ & 1500 & 1500 & \multicolumn{2}{|c|}{$\begin{array}{c}T_{\text {melt }} \text { is considered a fixed parameter } \\
\text { for both B500A and B500B steels }\end{array}$} \\
\hline Room temperature, ${ }^{\circ} \mathrm{C}$ & $T_{r}$ & 20 & 20 & {$[16,24]$} & {$[16,24]$} \\
\hline
\end{tabular}

Examples of values of the parameters $c_{1}, \ldots, c_{5}$ belonging to the JC model are given in Table 2. Eq. (5) indicates that this model is a function of three arguments $\varepsilon_{p}$, $\dot{\varepsilon}^{\prime}$ and $T_{h}$ or $\varepsilon_{p}, \quad \dot{\varepsilon}^{\prime}$ and $T$ if the dimensionless temperature $T_{h}$ is developed according to Eq. (3). Thus, we have to deal with the multivariate functions $\sigma_{J C}\left(\varepsilon_{p}, \dot{\varepsilon}^{\prime}, T_{h} \mid c_{1}, c_{2}, \ldots, c_{5}\right)$ or $\sigma_{J C}\left(\varepsilon_{p}, \dot{\varepsilon}^{\prime}, T \mid c_{1}, c_{2}, \ldots, c_{5}\right)$ that have five material-related parameters. If necessary, quasistatic strain rate $\dot{\varepsilon}_{s}$ and reference temperature $T_{r}$ can be added to the set of parameters of $\sigma_{J C}(\cdot)$. The presence of 
the relatively large number of parameters in $\sigma_{J C}(\cdot)$ generates a need to assess sensitivity of $\sigma_{J C}(\cdot)$ to these parameters. In our opinion, the global sensitivity analysis (GSA) is the best way to assess the dependence of $\sigma_{J C}(\cdot)$ on its parameters [18].

In the deterministic context, input information for GSA can be expressed by uniform probability distributions over parameter variation ranges, say, $\pm 20 \%$ variation ranges [18]. Values of the variation ranges are given in Table 2. GSA is based on a repetitive stochastic simulation of parameter values and computation of output values of $\sigma_{J C}(\cdot)$. Results of GSA will depend on the choice of values of the arguments $\varepsilon_{p}, \dot{\varepsilon}^{\prime}$ and $T$. The number of combinations of these values is infinite. Consequently, GSA has been limited only by a set of three values of $\varepsilon_{p}, \dot{\varepsilon}^{\prime}$ and $T$ given in the second columns of Table 3 and belonging to ranges of $\varepsilon_{p}, \dot{\varepsilon}^{\prime}$ and $T$ used in dynamic tests of B500A and B500B steels and reported in the articles [1] Fig. 2 presents two graphs of the function $\sigma_{J C}\left(\varepsilon_{p}, 400,400\right)$ drawn for B500A and B500B steels as well as four graphs of $\sigma_{J C}\left(\varepsilon_{p}, \dot{\varepsilon}^{\prime}, T\right)$ developed for two combinations $\left(1,20^{\circ} \mathrm{C}\right)$ and $\left(400,20^{\circ} \mathrm{C}\right)$ of the arguments $\left(\dot{\varepsilon}^{\prime}, T\right)$.

In line with the principles of GSA, the sensitivity analysis has been carried out for the function:

$$
\begin{aligned}
& \Sigma_{J C}\left(0.25,400,400 \mid C_{1}, \ldots, C_{5}, T_{r}\right)= \\
& =\left(C_{1}+C_{2} 0.25^{C_{3}}\right)\left(1+C_{4} \ln 400\right) \times \\
& \times\left(1-\left(\left(400-\tilde{T}_{r}\right) /\left(1500-\tilde{T}_{r}\right)\right)^{C_{5}}\right),
\end{aligned}
$$

where: the symbols $C_{1}, \ldots, C_{5}$ and $\tilde{T}_{r}$ are random parameter values and random room temperature, all uniformly distributed over the variation ranges given in Table 2, and $\Sigma_{J C}(\cdot)$ is the random stress expressed as function of the random variables $C_{1}$ to $C_{5}$ and $\tilde{T}_{r}$.

Results of GSA obtained for B500A and B500B steels and expressed by six first order GSA indices $S_{i}$ are given in columns 3 and 4 of Table 4 . The same table contains also results of GSA indices computed for the case where three arguments $\varepsilon_{p}, \dot{\varepsilon}^{\prime}$ and $T$ of $\sigma_{J C}(\cdot)$ were considered random input variables $\tilde{\varepsilon}_{p}, \tilde{\dot{\varepsilon}}^{\prime}$ and $\tilde{T}$ uniformly distributed over $\pm 20 \%$ variation ranges around the fixed values given in Table 3. GSA has been carried out for the function that includes nine random variables, namely:

$$
\begin{aligned}
& \Sigma_{J C}\left(\tilde{\varepsilon}_{p}, \tilde{\dot{\varepsilon}}^{\prime}, \tilde{T} \mid C_{1}, \ldots, C_{5}, T_{r}\right)= \\
& =\left(C_{1}+C_{2} \tilde{\varepsilon}_{p}^{C_{3}}\right)\left(1+C_{4} \ln \tilde{T}\right) \times \\
& \times\left(1-\left(\left(\tilde{T}-\tilde{T}_{r}\right) /\left(1500-\tilde{T}_{r}\right)\right)^{C_{5}}\right) .
\end{aligned}
$$

Nine first order GSA indices $S_{i}$ computed for this function are presented in columns 5 and 6 of Table 3 . The sum of the indices $S_{i}$ is close to $100 \%$, and therefore higher order sensitivity indices are not presented. It turned out that the stress $\sigma_{J C}(\cdot)$ is influenced mainly by the yield stress $c_{1}$, thermal softening parameter $c_{5}$ and strain rate hardening parameter $c_{4}$ in case of both $\mathrm{B} 500 \mathrm{~A}$ and $\mathrm{B} 500 \mathrm{~B}$ steels and both functions expressed by Eqs. (6) and (7). In case of the function given by Eq. (7), a relatively high sensitivity of $\sigma_{J C}(\cdot)$ with respect to the elevated temperature $T$ was found.

Table 3

Values of arguments of the JC model, $\varepsilon_{p}, \dot{\varepsilon}^{\prime}$ and $T$, used for sensitivity analyses

\begin{tabular}{|c|c|c|}
\hline Argument & Fixed value & $\pm 20 \%$ variation range \\
\hline \hline 1 & 2 & 3 \\
\hline \hline$\varepsilon_{p},-$ & $0.25^{*}$ & {$[0.2,0.3]^{*}$} \\
\hline$\dot{\varepsilon}^{\prime},-$ & 400 & {$[320,480]$} \\
\hline$T,{ }^{\circ} \mathrm{C}$ or $T_{h},-$ & $400(0.257)$ & $\begin{array}{c}{[320,480] \text { or }} \\
{[0.206,0.308]}\end{array}$ \\
\hline$*$ See the abscissa axis in Fig. 2 & \\
\hline
\end{tabular}

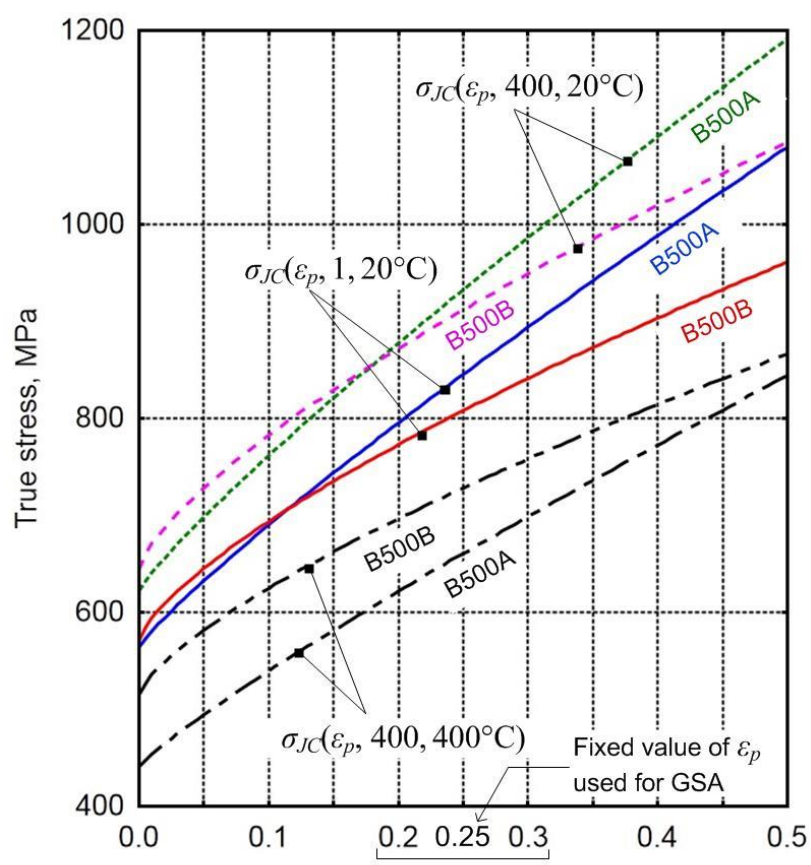

Variation range of $\varepsilon_{p}$ used for GSA

True plastic strain $\varepsilon_{p}$

Fig. 2 Graphs of the function $\sigma_{J C}\left(\varepsilon_{p}, \dot{\varepsilon}^{\prime}, T \mid c_{1}, c_{2}, \ldots, c_{5}\right)$ drawn for the parameter values given in Table 2

Table 4

First order global sensitivity indices $S_{i}$ computed for parameters and arguments of the JC model $\sigma_{J C}\left(\varepsilon_{p}, \dot{\varepsilon}^{\prime}, T \mid c_{1}, c_{2}, \ldots, c_{5}, T_{r}\right)$

\begin{tabular}{|c|c|c|c|c|c|}
\hline \multirow{2}{*}{$i$} & \multirow{2}{*}{$\begin{array}{c}\text { Input } \\
\text { variable }\end{array}$} & $\begin{array}{c}|c| \\
\text { B500A } \\
\text { steel }\end{array}$ & $\begin{array}{c}\text { B500B } \\
\text { steel }\end{array}$ & $\begin{array}{c}\text { B500A } \\
\text { steel }\end{array}$ & $\begin{array}{c}\text { B500B } \\
\text { steel }\end{array}$ \\
\hline \hline 1 & 2 & 3 & 4 & 5 & 6 \\
\hline \hline 1 & $c_{1}$ & $44.2(1)$ & $57.8(1)$ & $36.2(1)$ & $49.3(1)$ \\
\hline 2 & $c_{2}$ & $11.0(4)$ & $9.69(4)$ & $8.94(5)$ & $8.48(4)$ \\
\hline 3 & $c_{3}$ & $16.7(3)$ & $10.2(3)$ & $13.7(3)$ & $9.10(3)$ \\
\hline 4 & $c_{4}$ & $0.94(6)$ & $1.47(5)$ & $0.66(7)$ & $0.69(7)$ \\
\hline 5 & $c_{5}$ & $26.4(2)$ & $19.5(2)$ & $21.1(2)$ & $16.4(2)$ \\
\hline 6 & $T_{r}$ & $2.67(5)$ & $0.87(6)$ & $0.23(8)$ & $<0.001$ \\
\hline 7 & $\varepsilon_{p}$ & N/A & N/A & $6.89(6)$ & $4.40(6)$ \\
\hline 8 & $\dot{\varepsilon}^{\prime}$ & N/A & N/A & $0.02(9)$ & $<0.001$ \\
\hline 9 & $T$ & N/A & N/A & $12.9(4)$ & $7.87(5)$ \\
\hline
\end{tabular}




\subsection{Exploration of parameter estimation problems}

The parameters $c_{2}$ and $c_{3}$ are evaluated from the quasi-static true stress-strain record $\sigma_{s}-\varepsilon_{s}$ shown in Fig. 3. Values of $c_{2}$ and $c_{3}$ are results of a linear fit of the function that in typical symbols of regression analysis is expressed as:

$$
y_{s}=\beta_{0 s}+\beta_{1 s} x_{s},
$$

with $y_{s}=\ln \left\{\sigma_{s}-c_{1}\right\}=\ln \left\{\sigma_{s}-\sigma_{y}\right\} ; \quad \beta_{0 s}=\ln c_{2} ; \quad \beta_{1 s}=c_{3}$ and $x_{s}=\ln \varepsilon_{p}$. The data pairs used to fit the function in Eq. (8) may have the form:

$$
\begin{aligned}
& \left(y_{s j}, x_{s j}\right) \equiv\left(\ln \left\{\sigma_{s}\left(\varepsilon_{p j}\right)-\sigma_{y}\right\}, \ln \left\{\varepsilon_{p j}\right\}\right) \\
& \left(j=1,2, \ldots, n_{j}\right),
\end{aligned}
$$

where: $\varepsilon_{p 1}, \ldots, \varepsilon_{p j}, \ldots \varepsilon_{p n_{j}}$ is a series of $n_{j}$ values of plastic strain and $\sigma_{s}\left(\varepsilon_{p j}\right)$ is the quasi-static stress corresponding to the strain $\varepsilon_{p j}$ with $\sigma_{s}\left(\varepsilon_{p 1}\right)=\sigma_{y}$ (Fig. 3). An example of fitting the function given by Eq. (8) to the data $\left(y_{s j}, x_{s j}\right)$ is presented by Lin et al. [17].

The value of the strain rate hardening parameter $c_{4}$ is determined by means of at least two schemes (see [15] and references cited therein). The first scheme is based on the difference between the quasi-static yield stress $\sigma_{y}$ the dynamic yield stress $\sigma_{d 1}\left(\dot{\varepsilon}^{\prime}\right)$ at given strain rate $\dot{\varepsilon}^{\prime}$ [6]. Both $\sigma_{y}$ and $\sigma_{d 1}\left(\dot{\varepsilon}^{\prime}\right)$ are illustrated in Fig. 2. The second and more advanced scheme utilises a set of quasi-static stresses $\left\{\sigma_{s}\left(\varepsilon_{p j}\right), j=1,2, \ldots, n_{j}\right\}$ determined for the series of the plastic strain $\varepsilon_{p 1}, \ldots, \varepsilon_{p n_{j}}$ and corresponding sets of dynamic stresses determined at $n_{k}$ strain rate values $\dot{\varepsilon}_{k}^{\prime}$, namely, $\left\{\left\{\sigma_{d}\left(\varepsilon_{p j}, \dot{\varepsilon}_{k}^{\prime}\right), j=1,2, \ldots, n_{j}\right\}, k=1,2, \ldots, n_{k}\right\}$. These sets are visualised by Fig. 2 . The second scheme uses averages of the dynamic increase factors $\sigma_{d}\left(\varepsilon_{p j}, \dot{\varepsilon}_{k}^{\prime}\right) / \sigma_{s}\left(\varepsilon_{p j}\right)$ calculated over the range of plastic strain $\left[\varepsilon_{p 1}, \varepsilon_{p n_{j}}\right]$ at each strain rate $\dot{\varepsilon}_{k}$ :

$$
\overline{D I F}\left(\dot{\varepsilon}_{k}^{\prime}\right)=n_{j}^{-1} \sum_{j=1}^{n_{j}} \sigma_{d}\left(\varepsilon_{p j}, \dot{\varepsilon}_{k}^{\prime}\right) / \sigma_{s}\left(\varepsilon_{p j}\right)
$$

The value of $c_{4}$ results from a linear fit of the function that in terms of regression analysis is given by:

$$
y_{c}=\beta_{0 c}+\beta_{1 c} x_{c}=1+\beta_{1 c} x_{c}
$$

with $y_{c}=\overline{D I F}(\dot{\varepsilon}) ; \quad \beta_{0 c}=1 ;, \beta_{1 c}=c_{4}$ and $x=\ln \left(\dot{\varepsilon}^{\prime}\right)$. The data pairs used to fit the function in Eq. (10) has the form:

$$
\left(y_{c k}, x_{c k}\right)=\left(\overline{D I F}\left(\dot{\varepsilon}_{k}^{\prime}\right), \ln \left\{\dot{\varepsilon}_{k}^{\prime}\right\}\right)\left(k=1,2, \ldots, n_{k}\right) .
$$

Examples of fitting the function given by Eq. (11) to the data $\left(y_{c k}, x_{c k}\right)$ are presented by Lin et al. and Zeng et al. $[15,17]$.
The thermal softening parameter $c_{5}$ is strain rate independent in the JC model $[4,5]$. In this case, a value of $c_{5}$ is determined with static data, that is, on the basis of the equation:

$$
\sigma_{s}\left(\varepsilon_{p}, T_{h}\right)=\left(c_{1}+c_{2} \varepsilon_{p}^{c_{3}}\right)\left(1-T_{h}^{c_{5}}\right)
$$

brought to the form:

$$
\ln \left\{1-\frac{\sigma_{s}\left(\varepsilon_{p}, T_{h}\right)}{c_{1}+c_{2} \varepsilon_{p}^{c_{3}}}\right\}=c_{5} \ln T_{h},
$$

where: $\sigma_{s}\left(\varepsilon_{p}, T_{h}\right)$ is the quasi-static stress at given plastic strain $\varepsilon_{p}$ and temperature $T_{h}$. The dependence of $c_{5}$ on $\varepsilon_{p}$ can be handled similarly to the case of the strain rate hardening parameter $c_{4}$. For a series of strain values, $\left\{\varepsilon_{p j}, j=1\right.$, $\left.2, \ldots, n_{j}\right\}$ and a series of temperature values $\left\{T_{h l}, l=1,2, \ldots\right.$, $\left.n_{j}\right\}$, the static data will be expressed by the stresses $\sigma_{s}\left(\varepsilon_{p j}, T_{h k}\right)$ (Fig. 3). The pairs of data used for a linear fit will have the form:

$$
\left(y_{T l}, x_{T l}\right) \equiv\left(\overline{T D F}\left(T_{h l}\right), \ln \left\{T_{h l}\right\}\right) \quad\left(l=1,2, \ldots, n_{j}\right) .
$$

where: $\overline{T D F}\left(T_{h l}\right)$ is the "thermal decrease factor" calculated for each $T_{h l}$ as an average of the stress ratios:

$$
\overline{T D F}\left(T_{h l}\right)=n_{j}^{-1} \sum_{j=1}^{n_{j}} \sigma_{s}\left(\varepsilon_{p j}, T_{h l}\right) /\left(c_{1}+c_{2} \varepsilon_{p j}^{c_{3}}\right),
$$

or

$$
\overline{T D F}\left(T_{h l}\right)=n_{j}^{-1} \sum_{j=1}^{n_{j}} \sigma_{s}\left(\varepsilon_{p j}, T_{h l}\right) / \sigma_{s}\left(\varepsilon_{p j}, 0\right),
$$

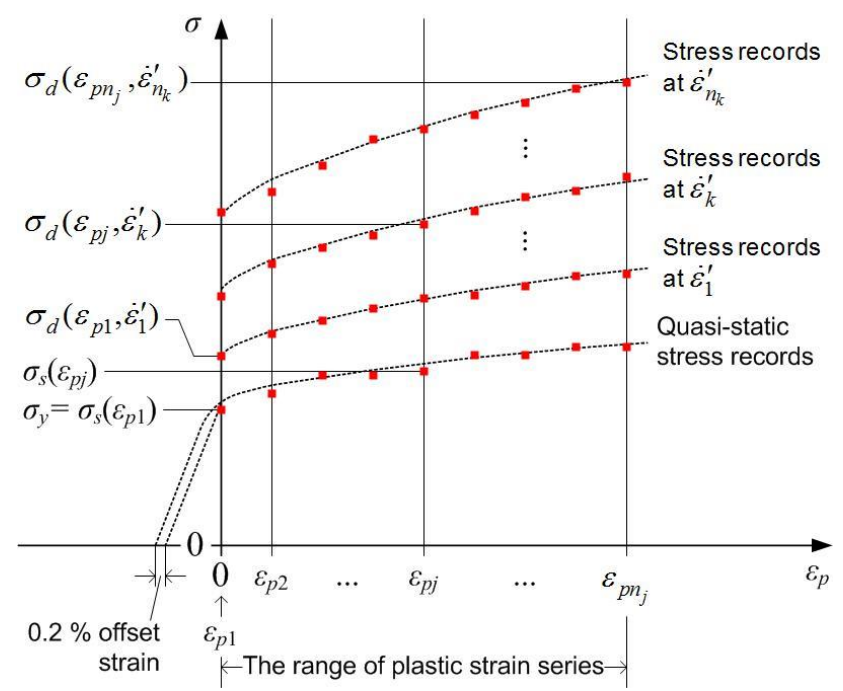

Fig. 3 The scheme of data used to determine parameters of the isothermal JC model by means of $n_{k}+1$ stressstrain records $\sigma_{i}-\varepsilon_{i}\left(i=1,2, \ldots, n_{k}+1\right)$

where: $\sigma_{s}\left(\varepsilon_{p j}, 0\right)$ is the quasi-static stress measured at the temperature $T_{h}=0$ (at $T=T_{r}$ in Eq. (3)) and $\left(c_{1}+c_{2} \varepsilon_{p j}^{c_{3}}\right)$ is an estimate of the quasi-static stress $\sigma_{s}\left(\varepsilon_{p j}, 0\right)$ calculated 
with the parameter values $c_{1}$ to $c_{3}$ obtained from static data at the room temperature $T_{r}$. Values of $c_{1}$ to $c_{3}$ can be acquired not necessarily in the same experiment that yielded the stresses $\sigma_{s}\left(\varepsilon_{p j}, T_{h k}\right)$.

The value of $c_{5}$ should be a result of a linear fit of the function that in notation of regression analysis can be expressed as:

$$
y_{T}=\beta_{T} x_{T},
$$

where: $y_{T}=\overline{T D F}\left(T_{h l}\right) ; \beta_{T}=c_{5}$ and $x_{T}=\ln \left(T_{h}\right)$. The data pairs $\left(y_{T l}, x_{T l}\right)$ used to estimate the slope parameter $\beta_{T}$ are defined by Eq. (15). An example of fitting the liner function given by Eq. (17) to the data $\left(y_{T l}, x_{T l}\right)$ is presented in the paper [17].

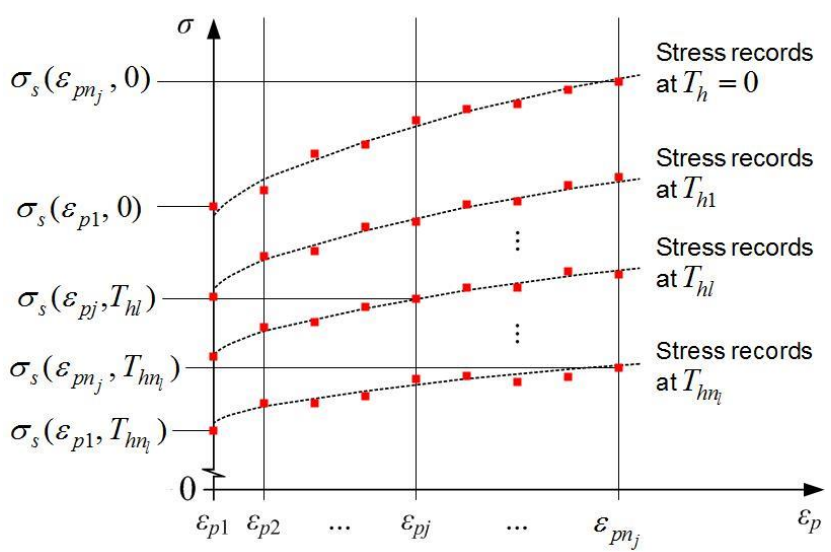

Fig. 4 The scheme of data used to determine the parameter of thermal softening in the JC model

An alternative approach to the evaluation of the thermal softening parameter $c_{5}$ assumes that $c_{5}$ depends on the strain rate $\dot{\varepsilon}$ and temperature $T$ [1]. It is suggested to evaluate $c_{5}$ by means of the equation:

$$
c_{5}\left(\dot{\varepsilon}, T_{h l}\right)=\log \left(1-r\left(\dot{\varepsilon}, T_{h l}\right)\right) / \log \left(T_{h l}\right), \text {, }
$$

with

$$
r\left(\dot{\varepsilon}, T_{h l}\right)=A\left(\dot{\varepsilon}, T_{h l}\right) / A\left(\dot{\varepsilon}, T_{h}\right) \text { and } T_{h l}>0, T_{h}=0,(18 \mathrm{~b})
$$

where: $T_{h}=T_{h}\left(T_{r}\right)$ is the value of the dimensionless temperature at the reference (room) temperature $T_{r}$. (see Eq. (3)), $T_{h l .}=T_{h}\left(T_{l}\right)$. is the value of $T_{h}$ at the elevated temperature $T_{l}$ $T_{l}>T_{r}, A\left(\dot{\varepsilon}, T_{h l}\right)$ and $A\left(\dot{\varepsilon}, T_{h}\right)$ are the areas below true stress versus true strain records obtained at the temperatures $T_{h l}$ and $T_{h}$, respectively (Fig. 5). An example of a calculation of the values $c_{5}\left(\dot{\varepsilon}, T_{h l}\right)$ for five different temperatures and two values of strain rate is provided by Forni et al. [3].

The ratio $A\left(\dot{\varepsilon}, T_{h l}\right) / A\left(\dot{\varepsilon}, T_{h}\right)$ is interpreted as the thermal softening reduction factor [3]. Formally, this ratio expresses proportionality of two averages of the stress strain functions over a given interval of strain values, for instance, the interval $\left[0, \varepsilon_{p n_{j}}\right]$ shown in Fig. 4. An application of this averaging procedure makes the estimate of the parameter $c_{5}$ closely related to the averaging expressed by Eqs. (17). At the same time, the key difference between these two procedures is the use of static data in case of the ratios $\sigma_{s}\left(\varepsilon_{p j}, T_{h l}\right) / \sigma_{s}\left(\varepsilon_{p j}, 0\right)$ and dynamic data measured at the strain rates $\dot{\varepsilon}$ in case of the ratios $A\left(\dot{\varepsilon}, T_{h l}\right) / A\left(\dot{\varepsilon}, T_{h}\right)$. The parameter $c_{5}\left(\dot{\varepsilon}, T_{h l}\right)$ is a bivariate function. In terms of a regression analysis, $c_{5}\left(\dot{\varepsilon}, T_{h l}\right)$ can be expressed as:

$$
y_{\varepsilon T}=f(\boldsymbol{x} \mid \boldsymbol{\beta}),
$$

with $y_{\varepsilon Y}=c_{5}$ and $\boldsymbol{x}=\left(\dot{\varepsilon}, T_{h l}\right)$, where: $\boldsymbol{\beta}$ is a vector of regression parameters. Limited experimental data indicates that $f(\boldsymbol{x} \mid \boldsymbol{\beta})$ should be a nonlinear function of strain rate and temperature $[1,3]$. Attempts to develop a nonlinear bivariate function $f(\boldsymbol{x} \mid \boldsymbol{\beta})$ or to transform recorded values of $c_{5}, \dot{\varepsilon}$ and $T_{h l}$ and apply new data to fitting a linear regression model $y_{\varepsilon T}^{\prime}=\boldsymbol{x}^{\prime} \boldsymbol{\beta}^{\prime}$ with regressand $y_{\varepsilon T}^{\prime}$, regressors $\boldsymbol{x}^{\prime}$ and regression coefficients $\boldsymbol{\beta}^{\prime}$ do not seem to be available.

The use of the multiplication factor $\left(1-T_{h}^{c_{5}}\right)$ in the JC model expressed by Eq. (5) means that temperature and strain rate are considered in a decoupled form. This feature is considered to be one of the shortcomings of JC model, because flow stresses of metals are highly affected by the coupled effect of temperature and strain rate [19]. However, any quantitative measures of this inconsistency are not provided by authors of this criticism. At the same time, the JC model is praised for its simplicity, a relatively simple parameter estimation and easiness of implementation in computer codes.

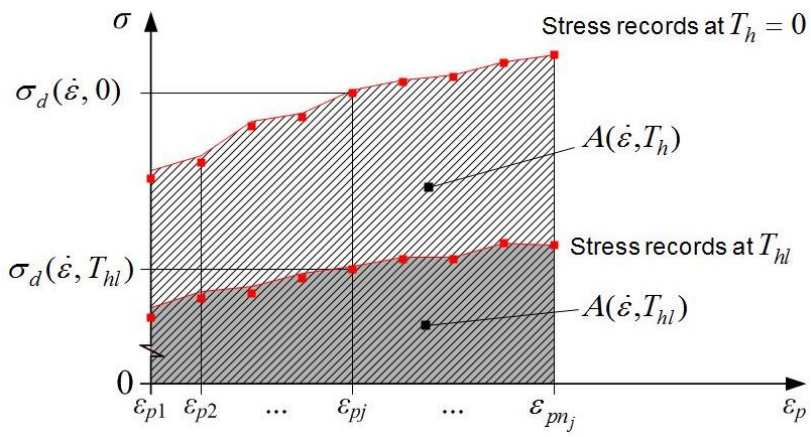

Fig. 5 An illustration of the areas below true stress versus true strain records, $A\left(\dot{\varepsilon}, T_{h l}\right)$ and $A\left(\dot{\varepsilon}, T_{h}\right)$, obtained at the temperatures $T_{h l}$ and $T_{h}$

\section{Statistical examination of the Johnson-Cook model}

\subsection{Random variability of stress-strain records}

The JC model was not developed to describe a yield plateau; however, it can be readily adapted to model the yield stress by assuming that the plastic strain $\varepsilon_{p}$ is equal to zero, namely:

$$
\sigma_{y}(\dot{\varepsilon})=c_{1}\left(1+c_{4} \ln \dot{\varepsilon}^{\prime}\right) .
$$

Results of GSA presented in Sec. 3.1 indicate that the JC model is most sensitive to the model component $c_{1}$ (yield stress or $0.2 \%$ offset stress) and relatively insensitive to the parameter $c_{4}$ and the strain rate $\dot{\varepsilon}^{\prime}$ (Table 4). This 
naturally raises the question related to the influence of the variability

Mechanical properties of steel are prone to a natural statistical variation. The variability expressed by the coefficient of variation (COV) for yield stress $\sigma_{y}$ of general population of reinforcing bars is around $4-11 \%$ [20]. The $\mathrm{COV}$ of the modulus of elasticity of reinforcement steels from the same population is equal to $3.3 \%$. The strain-hardening modulus of construction steel sections has values of COV around $8 \%$ [21]. COVs of yield strength of B500A and $\mathrm{B} 500 \mathrm{~B}$ reinforcing bars with diameters of 6,8 and $10 \mathrm{~mm}$ are $2.9 \%, 6.6 \%$ and $20.3 \%$, respectively [22]. The above values of COVs are not excessively large; however, the random variation represented by them is not ignored in assessing the reliability of reinforced concrete structures [20].

Recorded stress-strain curves will inevitably differ randomly even in the case where test specimens are prepared from the bars having the same diameter, made of same steel and are subjected to the same a dynamic strain rate $\dot{\varepsilon}$

. This random variation is illustrated for the $\sigma_{\text {true }}-\varepsilon_{\text {true }}$ curves in Fig. 2. The variation of the stress-strain records leads to variation of values related to them. If a set of $n$ stress-strain records is considered and the index $i$ used to refer to elements of this set, each record $\sigma_{\text {true }, i}-\varepsilon_{\text {true }, i}$ generates at least the following values related to the given strain rate $\dot{\varepsilon}$ (Fig. 2):

- pair of strains $\left(\varepsilon_{y i}(\dot{\varepsilon}), \varepsilon_{u i}(\dot{\varepsilon})\right)$ representing onset and end of the hardening stage;

- yield stress $\sigma_{y i}(\dot{\varepsilon})$;

- true stress $\sigma_{\text {true }, i}\left(\varepsilon^{\prime}, \dot{\varepsilon}\right)$ related to a given value of the true strain, $\varepsilon^{\prime}$.

Random variation of the recorded signals ("records" in what follows) $\sigma_{\text {true }, i}-\varepsilon_{\text {true }, i}(i=1,2, \ldots, n)$ generates two results:

1. Values of onset and end of hardening stage represented by the statistical samples $\left\{\varepsilon_{y i}(\dot{\varepsilon}), i=1,2, \ldots, n\right\}$ and $\left\{\varepsilon_{u i}(\dot{\varepsilon}), i=1,2, \ldots, n\right\}$ are "blurred" and there is no single interval of plastic strain values for fitting the strainhardening model $\left(c_{1}+c_{2} \varepsilon_{p}^{c_{3}}\right)\left(1+c_{4} \ln \dot{\varepsilon}^{\prime}\right)$.

2. The stress related to any given strain $\varepsilon^{\prime}$ and given strain rate $\dot{\varepsilon}$ is also "blurred" and represented by the statistical sample $\left\{\sigma_{\text {true }, i}\left(\varepsilon^{\prime}, \dot{\varepsilon}\right), i=1,2, \ldots, n\right\}$.

With these two results, fitting the strain-hardening model $\left(c_{1}+c_{2} \varepsilon_{p}^{c_{3}}\right)\left(1+c_{4} \ln \dot{\varepsilon}^{\prime}\right)$ becomes a statistical problem. This problem can be approached at least in three approaches.

Firstly, variance of the samples consisting of the values $\sigma_{y i}(\dot{\varepsilon}), \varepsilon_{y i}(\dot{\varepsilon}), \sigma_{\text {true }, i}\left(\varepsilon^{\prime}, \dot{\varepsilon}\right)$ and $\varepsilon_{u i}(\dot{\varepsilon})$ can be ignored if this variance is negligible or, what is more likely, the number of records, $n$, is very small. This approach is prevailing in the literature cited before and related to stressstrain modelling. Values of the parameters $c_{1}$ to $c_{4}$ are usually evaluated by fitting the strain-hardening model to solely one record $\sigma_{\text {true }, i}-\varepsilon_{\text {true }, i}$.

Secondly, the problem can be "averaged out" by fitting the models $\left(c_{1}+c_{2} \varepsilon_{p}^{c_{3}}\right)$ and $\left(c_{1}+c_{2} \varepsilon_{p}^{c_{3}}\right)\left(1+c_{4} \ln \dot{\varepsilon}^{\prime}\right)$ to average values of the samples mentioned in the previous item. This fitting is schematically illustrated in Fig. 6.

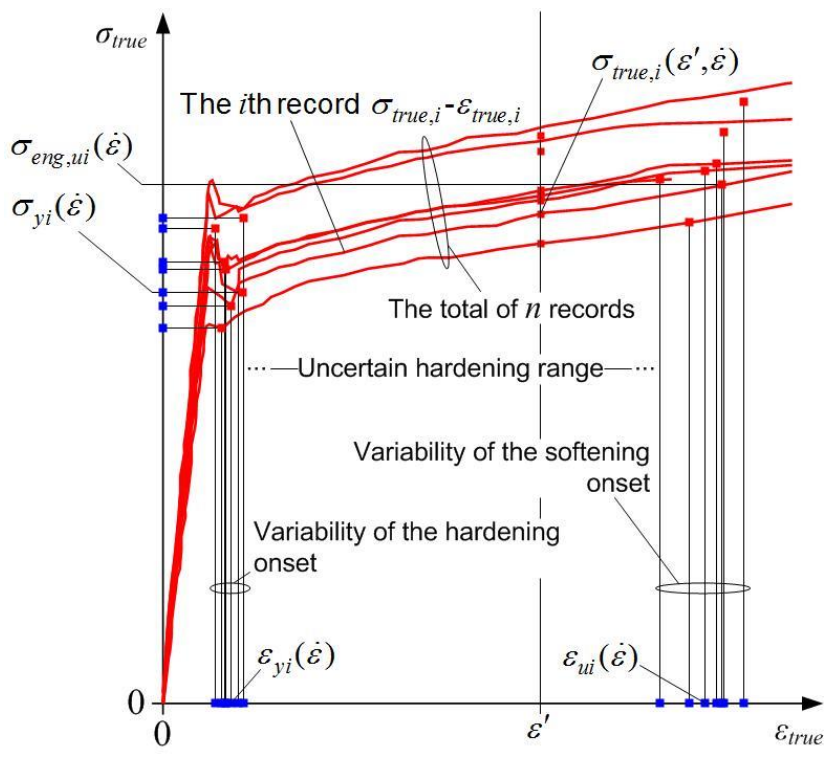

Fig. 6 Schematic illustration of the random variation of the records $\sigma_{\text {true }, i}-\varepsilon_{\text {true }, i}$ related to a given strain rate $\dot{\varepsilon}$ and resulting variation of specific values of stresses and strains

Thirdly, the problem can be solved by fitting the models $\left(c_{1}+c_{2} \varepsilon_{p}^{c_{3}}\right)$ and $\left(c_{1}+c_{2} \varepsilon_{p}^{c_{3}}\right)\left(1+c_{4} \ln \dot{\varepsilon}^{\prime}\right)$ to a set of conservatively high and conservatively low estimates of static and dynamic stress values, respectively. Our suggestion is to use either conservative percentiles or limits of onesided confidence intervals calculated for means of random static and dynamic stresses.

The first natural candidate for the conservative representation of random dynamic and static stress at given strain value $\varepsilon_{p}$ are the low $q$-percentile $\sigma_{\text {true }, q}\left(\varepsilon_{p}, \dot{\varepsilon}\right)$ and the high $1-q$-percentile $\sigma_{\text {true } 1-q}\left(\varepsilon_{p}, 1\right)$. They are illustrated in Fig. 7 for the true strain value $\varepsilon^{\prime \prime}$. The levels $q$ and $1-q$ can be equal, for instance, to $10 \%$ and $90 \%$, respectively.

Fitting the strain-hardening models $\left(c_{1}+c_{2} \varepsilon_{p}^{c_{3}}\right)$ and $\left(c_{1}+c_{2} \varepsilon_{p}^{c_{3}}\right)\left(1+c_{4} \ln \dot{\varepsilon}^{\prime}\right)$ to conservative percentiles $\sigma_{\text {true }, q}\left(\varepsilon_{p}, \dot{\varepsilon}\right)$ and $\sigma_{\text {true }, 1-q}\left(\varepsilon_{p}, 1\right)$ will allow to specify a statistically conservative DIF related to a given plastic strain $\varepsilon_{p}$ and strain rate $\dot{\varepsilon}$, namely:

$$
\operatorname{DIF}\left(\varepsilon_{p}, \dot{\varepsilon}\right)=\sigma_{J C, q}\left(\varepsilon_{p}, \dot{\varepsilon}^{\prime}\right) / \sigma_{J C, 1-q}\left(\varepsilon_{p}, 1\right)
$$

where: $\sigma_{J C, q}\left(\varepsilon_{p}, \dot{\varepsilon}^{\prime}\right)$ is the JC model fitted to the $q$-percentiles of dynamic stress and $\sigma_{J C, 1-q}\left(\varepsilon_{p}, 1\right)$ is the quasi-static JC model fitted to $1-q$-percentiles of this stress. A choice of the percentage $q$ allows to control the conservativeness of the factor $\operatorname{DIF}\left(\varepsilon_{p}, \dot{\varepsilon}\right)$. The greater is $q$ and, the lesser and more conservative will be the factor $\operatorname{DIF}\left(\varepsilon_{p}, \dot{\varepsilon}\right)$. 


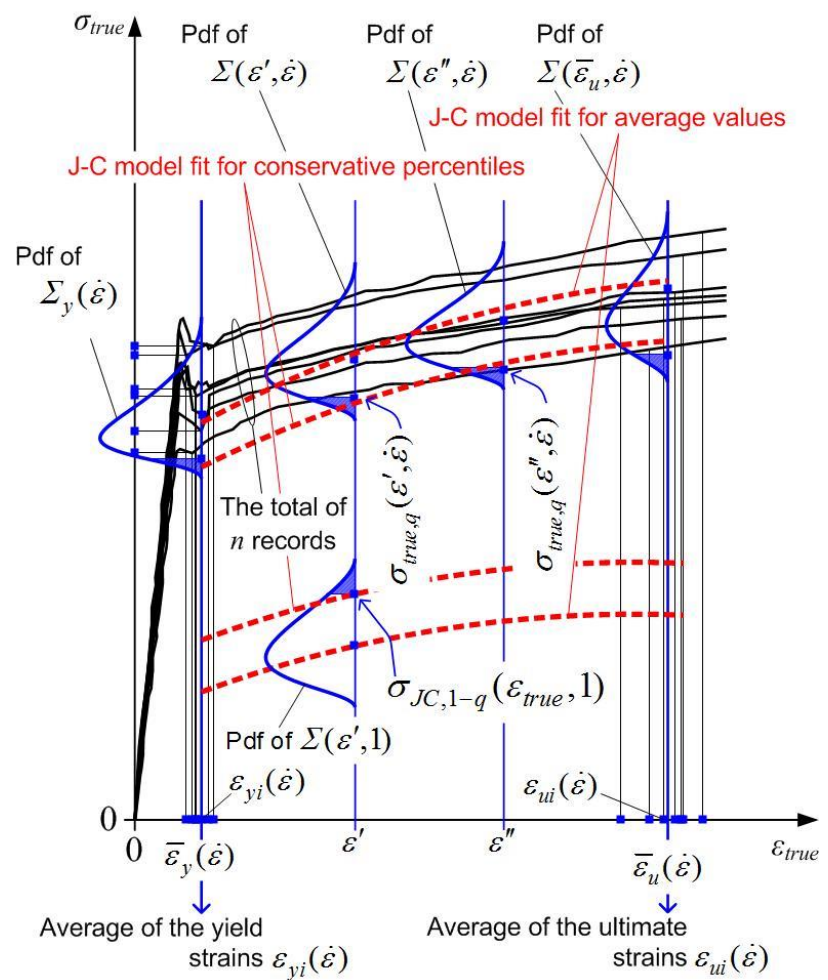

Fig. 7 Two possibilities of fitting the JC model to a set of $n$ records $\sigma_{\text {true }, i}-\varepsilon_{\text {true }, i}$ records: fitting the model to average stress values related to given strain values and fitting to conservative percentiles of stress values

Despite the desirable separation ensured by the percentile levels $q$ and $1-q$, the use of the percentiles $\sigma_{\text {true }, q}\left(\varepsilon_{p}, \dot{\varepsilon}\right)$ and $\sigma_{\text {true }, 1-q}\left(\varepsilon_{p}, 1\right)$ may pose at least two problems. Firstly, the value $\sigma_{\text {true }, 1-q}\left(\varepsilon_{p}, 1\right)$ can $q$ exceed the value $\sigma_{\text {true }, q}\left(\varepsilon_{p}, \dot{\varepsilon}\right)$ at highly distinct values of $q$ and $1-q$, say, 0.05 and 0.95 . In other words, the values $\sigma_{\text {true }, 1-q}\left(\varepsilon_{p}, 1\right)$ and $\sigma_{\text {true }, q}\left(\varepsilon_{p}, \dot{\varepsilon}\right)$ can "overlap". This problem is illustrated graphically in Fig. 8 and numerically by the example calculation given in Sec. 4.4. Secondly, the ratio $\sigma_{\text {true }, q}\left(\varepsilon_{p}, \dot{\varepsilon}\right) /$ $\sigma_{\text {true }, 1-q}\left(\varepsilon_{p}, 1\right)$ can be overly conservative. It is natural to seek that the factor $\operatorname{DIF}\left(\varepsilon_{p}, \dot{\varepsilon}\right)$ could express an average tendency with a slightly conservative value lying below this tendency. In our opinion, a less conservative value of $\operatorname{DIF}\left(\varepsilon_{p}, \dot{\varepsilon}\right)$ can be a ratio of limits of one-sided confidence intervals (CIs), $\bar{\mu}\left(\varepsilon_{p}, 1\right)$ and $\underline{\mu}\left(\varepsilon_{p}, \dot{\varepsilon}\right)$, calculated for the means $\mu\left(\varepsilon_{p}, 1\right)$ and $\mu\left(\varepsilon_{p}, \dot{\varepsilon}\right)$ of the random stresses $\Sigma\left(\varepsilon_{p}, 1\right)$ and $\Sigma\left(\varepsilon_{p}, \dot{\varepsilon}\right)$ represented by the probability density functions (pdfs) shown in Fig. 8. Thus the models $\left(c_{1}+c_{2} \varepsilon_{p}^{c_{3}}\right)$ and $\left(c_{1}+c_{2} \varepsilon_{p}^{c_{3}}\right)\left(1+c_{4} \ln \dot{\varepsilon}\right)$ can be fitted to the values $\bar{\mu}\left(\varepsilon_{p j}, 1\right)$ and $\underline{\mu}\left(\varepsilon_{p j}, \dot{\varepsilon}\right)$ calculated for a set of plastic strain values, say, $\left\{\varepsilon_{p j}, j=1,2, \ldots, n_{j}\right\}$. Let us denote these models by $\underline{\sigma}_{J C}\left(\varepsilon_{p}, \dot{\varepsilon}^{\prime}\right)$ and $\bar{\sigma}_{J C}\left(\varepsilon_{p}, 1\right)$. Then the value of $\operatorname{DIF}\left(\varepsilon_{p}, \dot{\varepsilon}\right)$ that is less conservative than the value defined by Eq. (21) can be expressed as:

$$
D I F\left(\varepsilon_{p}, \dot{\varepsilon}\right)=\underline{\sigma}_{J C}\left(\varepsilon_{p}, \dot{\varepsilon}^{\prime}\right) / \bar{\sigma}_{J C}\left(\varepsilon_{p}, 1\right) \text {. }
$$

The model $\operatorname{DIF}\left(\varepsilon_{p}, \dot{\varepsilon}\right)$ is a bivariate function of $\varepsilon_{p}$ and $\dot{\varepsilon}$. Data of dynamic and static tests is highly influenced not only by type of steel and bar diameter. Slightly different manufacturing processes of individual producers and possible peculiarities of test equipment may also contribute to statistical complexity of data necessary for fitting the model $\operatorname{DIF}\left(\varepsilon_{p}, \dot{\varepsilon}\right)$. Therefore, it makes sense to develop the model $\operatorname{DIF}\left(\varepsilon_{p}, \dot{\varepsilon}\right)$ for individual populations of steel products and by following the principles of statistical representativeness.

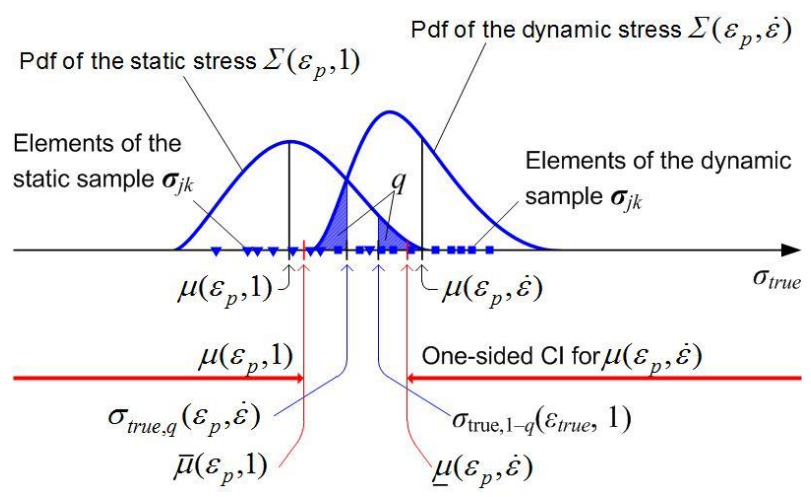

Fig. 8 The statistical situation related to uncertainties in static and dynamic stress expressed by random stress values $\Sigma\left(\varepsilon_{p}, 1\right)$ and $\Sigma\left(\varepsilon_{p}, \dot{\varepsilon}\right)$ and underlying samples of these values

Another natural adaptation of $\operatorname{DIF}\left(\varepsilon_{p}, \dot{\varepsilon}\right)$ could be a discretisation of values of the stress rate $\dot{\varepsilon}$. Such discretisation is a typical approach to carrying out dynamic tests and presenting results of these tests. For example, Cadoni and Forni [23] carried out experiments on S690QL structural steel under strain rates of 3, 30, 250, 450 and $950 \mathrm{~s}^{-1}$. A reasonable discretisation level for $\dot{\varepsilon}$ will allow to transfer the continuous function $\operatorname{DIF}(\cdot, \dot{\varepsilon})$ into discrete counterparts $\operatorname{DIF}\left(\cdot, \dot{\varepsilon}_{d}\right)(d=1,2, \ldots)$ and control the amount of discretisation error. Thus, the situation visualised by Fig. 6 may be seen as a data background of the individual function $\operatorname{DIF}\left(\cdot, \dot{\varepsilon}_{d}\right)$, that is, statistical information related to a given discrete value of stain rate, $\dot{\varepsilon}_{d}$.

An inclusion of the elevated temperature $T_{h}$ into the JC model can be statistically interpreted similarly to the interpretation of dynamically imposed stress at the room temperature $T_{r}$. As discussed in Sec. 3.2 and illustrated in Fig. 4, the prediction of stress at $T_{h}$ is based on the JC model with three arguments, $\sigma_{J C}\left(\varepsilon_{p}, \dot{\varepsilon}^{\prime}, T_{h} \mid \ldots, c_{5}\right)$. The thermal softening parameter $c_{5}$ must be evaluated by means of the static part of this model, $\sigma_{s}\left(\varepsilon_{p}, T_{h}\right)$, given by Eq. (13). This allows to introduce a temperature dependent DIF that is an extension of the DIF defined by Eq. (22), namely:

$$
\operatorname{DIF}\left(\varepsilon_{p}, \dot{\varepsilon}, T_{h}\right)=\sigma_{J C, 0.05}\left(\varepsilon_{p}, \dot{\varepsilon}, T_{h}\right) / \sigma_{s q}\left(\varepsilon_{p}, T_{h}\right),
$$

where: 0.05 and $q$ are the percentages that should be interpreted in the same way as in case of the temperature-insen- 
sitive factor $\operatorname{DIF}\left(\varepsilon_{p}, \dot{\varepsilon}\right)$ given by Eq. (22). The above considerations concerning the need to discretise the argument $\dot{\varepsilon}$ of $\operatorname{DIF}\left(\varepsilon_{p}, \dot{\varepsilon}\right)$ are also applicable to the second and third arguments of $\operatorname{DIF}\left(\varepsilon_{p}, \dot{\varepsilon}, T_{h}\right)$. It is apparent that the complexity of discretisation problem in case of $\operatorname{DIF}\left(., \dot{\varepsilon}, T_{h}\right)$ doubles due to the presence of the additional argument $T_{h}$. Arrangement of experiments on combined effect of high strain rate $\dot{\varepsilon}$ and elevated temperature $T_{h}$ demonstrates the need for a discretisation of $\dot{\varepsilon}$ and $T_{h}$. For instance, Cadoni and Forni [1] have carried out such experiments on B500A steel specimens by imposing them to strain rates of 250,500 and $900 \mathrm{~s}^{-1}$ and temperatures of 200,400 and $600{ }^{\circ} \mathrm{C}$.

The above considerations related to the statistical variability of the stress-strain records $\sigma_{\text {true }, i}-\varepsilon_{\text {true }, i}(i=1,2$, $\ldots, n)$ measured at different values of $\dot{\varepsilon}$ and $T_{h}$ presume an existence of a large number of these records, $n$ (Fig. 5). It desirable that each set consisting of $n$ records $\sigma_{\text {true }, i}-\varepsilon_{\text {true }, i}$ should be a statistical sample representative of a population of the reinforcement bars under study. The number $n$ can be viewed as a sample size. It must be large enough to estimate such quantities as the percentiles in Eqs. (22) and (23)) with sufficient statistical accuracy.

Results of the tests on such reinforcement steels as B500A and B500B reported in numerous articles cited above suggest a rational way of acquiring the sample \{ $\left.\sigma_{\text {true }, i}-\varepsilon_{\text {true }, i}, i=1,2, \ldots, n\right\}$. The sample elements $\sigma_{\text {true }, i}-\varepsilon_{\text {true }, i}$ should be drawn by carrying out repetitive tests on reinforcement bars belonging to the same type of steel and having the same nominal diameter.

To date large collections of statistical data that can be expressed in the form of the representative statistical samples $\left\{\sigma_{\text {true }, i}-\varepsilon_{\text {true }, i}, i=1,2, \ldots, n\right\}$ with elements $\sigma_{\text {true }, i}-\varepsilon_{\text {true }, i}$ covering the strain hardening range seem not to be available. However, some researchers are aware that the records $\sigma_{\text {true }, i}-\varepsilon_{\text {true }, i}$ are variable in statistical sense and present results of the tests that can be viewed as a rudimentary form of repetitive tests. For instance, Zeng et al. [14] carried out tests on HRB400E reinforcement bars by preparing and testing three nominally identical specimens cut from such bars.

\subsection{Proposal for statistical implementation}

In our opinion, reasons for the scarcity of statistical data related to strain hardening range are twofold:

1. The deterministic approach traditionally prevails in the field of dynamic increase modelling. The fact that the records $\sigma_{\text {true }, i}-\varepsilon_{\text {true }, i}$ are subject to statistical variation is not fully ignored. At the same time, attempts to express this variability explicitly have not been undertaken to the best of our knowledge.

2. The determination of uncertainty related to strain hardening properties for steel subjected to high strain rates and elevated temperatures is difficult. In addition, these properties have had relatively little attention, perhaps because they are seldom used for conventional design purposes. Reasons for that are mentioned by Melchers and Beck [20].
Despite the scarce data related to the repetitive records $\sigma_{\text {true }, i}-\varepsilon_{\text {true }, i}$, the variability of these records is clearly visible. This variability could be averaged out if dispersion measures of $\sigma_{\text {true }, i}-\varepsilon_{\text {true }, i}$ are small. The dispersion measures can be calculated for the values of the stresses $\sigma_{\text {true }}\left(\varepsilon_{p}, \dot{\varepsilon}\right)$ or $\sigma_{\text {true }}\left(\varepsilon_{p}, \dot{\varepsilon}, T_{h}\right)$ recorded for discretised values of $\varepsilon_{p}, \dot{\varepsilon}$ and $T_{h}$. In Figs. $3-5$ these values are represented by the sets $\left\{\varepsilon_{p j}, j=1,2, \ldots, n_{j}\right\},\left\{\dot{\varepsilon}_{k}, k=1,2, \ldots, n_{k}\right\}$ and $\left\{T_{h l}, l=1,2\right.$, $\left.\ldots, n_{l}\right\}$. For brevity, the further consideration will be limited by the temperature-insensitive case, that is, by dealing with the values $\sigma_{\text {true }}\left(\varepsilon_{p}, \dot{\varepsilon}\right)$. In this case, repetitive data allowing statistical analysis should be related to the stress $\sigma_{\text {true }}\left(\varepsilon_{p j}, \dot{\varepsilon}_{k}\right)$ and expressed by the statistical sample illustrated in (Fig. 6), namely, $\sigma_{j k}=\left\{\sigma_{\text {true }, i}\left(\varepsilon_{p j}, \dot{\varepsilon}_{k}\right), i=1,2, \ldots\right.$ $, n\}$.

The sample size $n$ will determine possibilities of modelling uncertainties related to dynamic stress-strain modelling in general and possibilities to estimate average values of $\sigma_{\text {true }}\left(\varepsilon_{p j}, \dot{\varepsilon}_{k}\right)$ and quantiles related to DIF expressed by Eq. (22). Currently, the values of $n$ that can be found in the literature are very small. Many repetitive tests were carried out for no more than three specimens, that is, $n \leq 3$ (see, e.g., [14]).

In the ideal case of a large sample $\sigma_{j k}$, uncertainty related to the stress $\sigma_{\text {true }}\left(\varepsilon_{p j}, \dot{\varepsilon}_{k}\right)$ can be modelled by a random variable $\Sigma\left(\varepsilon_{p j}, \dot{\varepsilon}_{k}\right)$ with a pdf illustrated in Fig. 7. If the sample $\sigma_{j k}$ seems to fit a particular probability distribution, a calculation of $q$ th percentiles $\sigma_{\text {true }, q}\left(\varepsilon_{p j}, \dot{\varepsilon}_{k}\right)$ becomes a trivial task.

In actual dynamic tests a question will be raised about the minimum size of the sample $\sigma_{j k}$. Procedures for the calculation of a required minimum sample size $n$ available in textbooks pertain to the estimation of such population parameters as mean and proportion as well as testing hypotheses about these parameters [24].

The minimum size of the sample $\sigma_{j k}$ related to fitting a probability distribution for $\Sigma\left(\varepsilon_{p j}, \dot{\varepsilon}_{k}\right)$ is expressed by required samples sizes for goodness-of-fit $(\mathrm{GoF})$ tests. However, practical tools are limited to a few highly specific procedures of distribution fitting, in particular to the parametric Pearson's test presuming large number of observations [25]. Procedures for the required sample size calculation have been developed for individual probability distributions, for instance, the generalised extreme value (GEV) distribution [26]. However, these procedures suppose naturally that the distribution type of the population under study is known in advance. Currently, this will not be the case in assessment of the probability distribution of $\Sigma\left(\varepsilon_{p j}, \dot{\varepsilon}_{k}\right)$. The required sample sizes estimated by the aforementioned procedures are large and can run into tens or several hundreds. Sample sizes of this magnitude are not typical for dynamic tests of steel, although they are technically achievable.

Literature on GoF procedures states that some nonparametric GoF tests can be applied even to the case where $n$ is as low as 6 to 10 observations [27]. Among them, the Anderson-Darling (AD) and Kolmogorov-Smirnov (KS) 
tests stand out. The $\mathrm{AD}$ test requires lesser number of data points in comparison to the KS test to properly reject the null hypothesis. Thus, the idea for quantifying uncertainty related to values of the stress $\sigma_{\text {true }}\left(\varepsilon_{p j}, \dot{\varepsilon}_{k}\right)$ is simple and can be implemented by a three-step procedure.

Firstly, a pilot sample $\sigma_{j k}$ consisting of, say, 10 elements should be collected and a coefficient of variation $(\mathrm{CoV})$ of $\sigma_{j k}$ calculated. If the value of $\mathrm{CoV}$ will not exceed $2-3$ percent, uncertainty related to the value $\sigma_{\text {true }}\left(\varepsilon_{p j}, \dot{\varepsilon}_{k}\right)$ can be ignored and this value could be estimated by the mean of $\sigma_{j k}$. This rejection criterion is based only on heuristic reasoning. A rigid mathematical criterion for ignoring uncertainty at small values of $\mathrm{CoV}$ does not seem to exist.

Secondly, the AD test should be applied to $\sigma_{j k}$ in the case that the variability of elements of $\sigma_{j k}$ cannot be neglected due to low value of CoV. Several hypothesized distributions could be used as sources of the sample $\sigma_{j k}$.

Thirdly, the hypothesized distribution with the best fitting results in line with the AD test should be chosen as the distribution of $\Sigma\left(\varepsilon_{p j}, \dot{\varepsilon}_{k}\right)$. The calculation of the quantiles of this distribution, $\sigma_{\text {true, } q}\left(\varepsilon_{p j}, \dot{\varepsilon}_{k}\right)$, will be a formal numerical task rather than a problem of statistical inference on the basis of data in the regions of distribution tails.

In theory, the conservative quantiles $\sigma_{\text {true }, q}\left(\varepsilon_{p j}, \dot{\varepsilon}_{k}\right)$ can be estimated directly from data rather than by $q$-quantiles of the probability distribution fitted to $\sigma_{j k}$. However, the calculation of empirical quantiles is problematic if data in the regions represented by them is absent or scarce. This will be precisely the case for a small size sample $\sigma_{j k}$ consisting of, say, ten elements. An estimation of quantiles with low values of $q$ will be impossible due lack or scarcity of data in the tail region of $\sigma_{j k}$. Thus, the estimation of the values $\sigma_{\text {true } q}\left(\varepsilon_{p j}, \dot{\varepsilon}_{k}\right)$ by $q$-quantiles of the probability distribution fitted to $\sigma_{j k}$ seems to be the most practicable, albeit not necessarily very accurate approach at the current practice and currently available possibilities of data acquisition.

\subsection{Numerical example}

Processing the data collected in dynamic tests on B500A steel is considered. The aim is to select a probability distribution of the random dynamic stress $\Sigma\left(\varepsilon_{p j}, \dot{\varepsilon}_{k}\right)$, provided that $\varepsilon_{p j}=0.03$ and $\dot{\varepsilon}_{k}=250 \mathrm{~s}^{-1}$. The sole value of $\sigma_{\text {true }, i}(0.03,250)$ that has been obtained in a dynamic test is $660 \mathrm{MPa}$ [23]. As the repetitive data related to the steel B500A and the pair $\left(0.03,250 \mathrm{~s}^{-1}\right)$ is not available, the sample $\sigma_{j k}$ consisting of 10 elements $\sigma_{\text {true }, i}(0.03,250)$ has been generated around the value $660 \mathrm{MPa}$ by means of a stochastic simulation, that is, $n=10$. The sample $\sigma_{j k}$ is given in Table 5.

Another pilot sample was composed of 10 values of the stress measured in static tests at $\varepsilon_{p j}=0.03$ and de- noted by the symbol $\sigma_{\text {true, } i}(0.03,1)$. This sample will be expressed in the form $\sigma_{s, j k}=\left\{\sigma_{\text {true }, i}\left(\varepsilon_{p j}, 1\right), i=1,2, \ldots, 10\right\}$. The sample $\sigma_{s, j k}$ was generated by means of a stochastic simulation and its average is relatively close to the stress value $610 \mathrm{MPa}$ recorded in static test $\varepsilon_{p j}=0.03$ [23]. The sample $\sigma_{s, j k}$ is given in Table 5 .

Table 5

Two small-size samples $\sigma_{s, j k}$ and $\sigma_{j k}$ used to calculate conservative estimates of uncertain static and dynamic stress related to the strain and strain rate pairs $\varepsilon_{p j}=0.03$ and $\dot{\varepsilon}_{k}=1 \mathrm{~s}^{-1}$ as well as $\varepsilon_{p j}=0.03$ and $\dot{\varepsilon}_{k}=250 \mathrm{~s}^{-1}$

\begin{tabular}{|c|c|c|}
\hline$i$ & $\begin{array}{c}\text { Static test stress } \\
\sigma_{\text {true }, i}(0.03,1)\end{array}$ & $\begin{array}{c}\text { Dynamic test stress } \\
\sigma_{\text {true }, i}(0.03,250)\end{array}$ \\
\hline 1 & 609.0 & 645.1 \\
\hline 2 & 583.2 & 741.3 \\
\hline 3 & 656.9 & 671.5 \\
\hline 4 & 594.2 & 615.4 \\
\hline 5 & 596.0 & 659.9 \\
\hline 6 & 628.0 & 633.3 \\
\hline 7 & 663.8 & 652.7 \\
\hline 8 & 644.8 & 687.0 \\
\hline 9 & 617.7 & 635.7 \\
\hline 10 & 627.0 & 743.9 \\
\hline
\end{tabular}

Results of processing the samples $\boldsymbol{\sigma}_{s, j k}$ and $\boldsymbol{\sigma}_{j k}$ are given in Table 6. Difference between mean values of $\mathrm{s}$ $\sigma_{s, j k}$ and $\sigma_{j k}$ is $46.5 \mathrm{MPa}$ and ranges of these samples overlap. Three hypothesized distributions have been used to fit probability distributions to $\sigma_{s, j k}$ and $\sigma_{j k}$ namely, twoparametric normal and lognormal distributions and threeparametric generalised extreme value (GEV) distribution.

The conservatively high 0.9 -quantile of the static stress distribution $\mathrm{N}(622.1,27.2)$ is equal to $657 \mathrm{MPa}$, whereas the conservatively low 0.1-quantile of the dynamic stress distribution GEV(647.1, 28.5, 0.1631) was calculated as $624 \mathrm{MPa}$. We see that the value of $657 \mathrm{MPa}$ related to static stress exceeds the value of $624.0 \mathrm{MPa}$ obtained for dynamic stress. This renders the specification of the factor value $\operatorname{DIF}(0.03,250)$ as ratio of conservative distribution quantiles unreasonable, because the ratio $624 / 657$ is less than one.

Goodness-of-fit results given in Table 6 reveal that the best fit to the static sample $\sigma_{s, j k}$ was obtained in case of normal distribution $\mathrm{N}(622.1,27.2)$ according to KS test and lognormal distribution $\mathrm{L}(6.43,0.0437)$ in line with AD test. As for the dynamic sample $\sigma_{s, j k}$, the best fit was obtained for GEV distribution $\operatorname{GEV}(647.1,28.5,0.1631)$ according to both $\mathrm{KS}$ and $\mathrm{AD}$ tests. The $\mathrm{KS}$ p-value 0.9872 calculated for $\mathrm{N}(622.1,27.2)$ was slightly less than the AD p-value 0.9929 obtained for $\mathrm{L}(6.43,0.0437)$. Therefore the normal distribution $\mathrm{N}(622.1,27.2)$ was assumed as the best fit to the static sample $\sigma_{s, j k}$.

An alternative and less conservative approach is to choose the value of $\operatorname{DIF}(0.03,250)$ as a ratio of two limits of one-sided CIs calculated for means of the random stress values $\Sigma(0.03,250)$ and $\Sigma(0.03,1)$. The probability of $90 \%$ was chosen as a not overly conservative confidence 
level of two one-sided CIs used to specify a value of $D I F(0.03,250)$. Limits of upper CI and lower CI were calculated for the means of random static stress $\Sigma(0.03,1)$ and random dynamic stress $\Sigma(0.03,250)$, respectively. Classical and bootstrap confidence intervals were obtained and are presented in Table 6.

Table 6

Descriptive measures of the sample of static stress values, $\sigma_{s, j k}$, and the sample of dynamic stress values, $\sigma_{j k}$

\begin{tabular}{|c|c|c|}
\hline Measure(s) & Sample $\sigma_{s, j k}$ & Sample $\sigma_{j k}$ \\
\hline Mean & $622.1 \mathrm{MPa}$ & $668.6 \mathrm{MPa}$ \\
\hline $\mathrm{CoV}$ & $4.38 \%$ & $6.57 \%$ \\
\hline Skewness & 0.1833 & 0.9376 \\
\hline Minimum & $583.2 \mathrm{MPa}$ & $615.4 \mathrm{MPa}$ \\
\hline Maximum & $663.8 \mathrm{MPa}$ & $743.9 \mathrm{MPa}$ \\
\hline Range & $80.56 \mathrm{MPa}$ & $128.8 \mathrm{MPa}$ \\
\hline & \multicolumn{2}{|c|}{ Normal distribution } \\
\hline Parameter estimates & $622.1,27.3$ & $668.6,6.57$ \\
\hline KS d & $0.13029^{\mathrm{a}}$ & 0.1785 \\
\hline KS p-value & 0.9872 & 0.8541 \\
\hline AD stat & 0.1945 & 0.5129 \\
\hline \multirow[t]{2}{*}{ AD p-value } & 0.9916 & 0.7295 \\
\hline & \multicolumn{2}{|c|}{ Lognormal distribution } \\
\hline Parameter estimates & $6.432,0.0437$ & $6.503,0.0643$ \\
\hline KS d & 0.1310 & 0.1692 \\
\hline KS p-value & 0.9865 & 0.8931 \\
\hline AD stat & $0.1886^{\mathrm{b}}$ & 0.4549 \\
\hline AD p-value & 0.9929 & 0.7893 \\
\hline \multicolumn{3}{|c|}{ Generalised extreme value (GEV) distribution } \\
\hline Parameter estimates & $\begin{array}{c}613.3,25.36 \\
-0.3083\end{array}$ & $\begin{array}{l}647.1,28.5 \\
0.1631\end{array}$ \\
\hline KS d & 0.1433 & 0.1312 \\
\hline KS p-value & 0.9685 & 0.986 \\
\hline AD stat & 0.2385 & 0.1880 \\
\hline AD p-value & 0.9762 & 0.9930 \\
\hline Best fit distribution & $\mathrm{N} \mathrm{N}(622.1,27.2)$ & (GEV $(647.1, \ldots)$ \\
\hline 0.9 quantile of best fit & $657 \mathrm{MPa}$ & N/A \\
\hline 0.1 quantile of best fit & N/A & $624.0 \mathrm{MPa}$ \\
\hline $\begin{array}{c}\text { One-sided } 90 \% \text { clas- } \\
\text { sical CIs }{ }^{\mathrm{c}}\end{array}$ & $\begin{array}{c}\text { upper interval } \\
{[0,634.1 \mathrm{MPa}]}\end{array}$ & $\begin{array}{c}\text { upper interval } \\
{[634.0 \mathrm{MPa}, \infty[}\end{array}$ \\
\hline $\begin{array}{l}\text { One-sided } 90 \% \text { boot- } \\
\text { strap CIs }^{\mathrm{d}}\end{array}$ & $\begin{array}{c}\text { upper interval } \\
{[0,632.4 \mathrm{MPa}]}\end{array}$ & $\begin{array}{l}\text { lower interval } \\
{[649.5 \mathrm{MPa}, \infty[}\end{array}$ \\
\hline Ratio of CI limits & \multicolumn{2}{|c|}{$643.1 / 634.0=1.014$} \\
\hline Ratio of CI limits & \multicolumn{2}{|c|}{$649.5 / 632.4=1.027$} \\
\hline Ratio of means & \multicolumn{2}{|c|}{$668.6 / 622.1=1.075$} \\
\hline \multicolumn{3}{|c|}{$\begin{array}{l}\text { a The colour } \square \text { denotes the best fit according to the KS test. } \\
\text { b The colour } \square \text { denotes the best fit according to the AD test. } \\
{ }^{c} \text { CI for the mean calculated with the Student's quantile } \\
t_{9,0.90} \text { equal to } 1.383 \text {. } \\
{ }^{d} \text { CI for the mean calculated as the } 900^{\text {th }}\left(100^{\text {th }}\right) \text { element of } \\
\text { an ordered sample consisting of } 1000 \text { means of bootstrap } \\
\text { samples [28]. }\end{array}$} \\
\hline
\end{tabular}

The difference between the limits of classical and bootstrap CIs is relatively low. However, the bootstrap CI seems to be more robust, because it does not depend on theoretical assumptions underlying the classical CI [28]. The ratio of the bootstrap CI limits, $649.5 / 632.4$, is equal to 1.027 (Table 6). This means a dynamic increase of stress by
$2.7 \%$ and it can be used as a conservative estimate of the factor $\operatorname{DIF}(0.03,250)$. The ratio of the means of the samples $\sigma_{s, j k}$ and $\sigma_{j k}$ indicates an increase by $7.5 \%$. Thus, the number 1.027 can be viewed as a more cautious value of $\operatorname{DIF}(0.03,250)$ than the ratio of sample means, 1.075. In line with Eq. (23)), we can write that:

$$
D I F(0.03,250)=\frac{\mu(0.03,250)}{\bar{\mu}(0.03,1)}=\frac{649.5}{632.4}=1.027 .
$$

A repetition of the above calculation for a series of the plastic strain $\left\{\varepsilon_{p j}, j=1,2, \ldots, n_{j}\right\}$ will yield two sets of CI limits, $\left\{\bar{\mu}\left(\varepsilon_{p}, 1\right), j=1,2, \ldots, n_{j}\right\}$ and $\left\{\underline{\mu}\left(\varepsilon_{p}, \dot{\varepsilon}\right), j=\right.$ $\left.1,2, \ldots, n_{j}\right\}$, to which the strain hardening components of JC model, $\left(c_{1}+c_{2} \varepsilon_{p}^{c_{3}}\right)$ and $\left(c_{1}+c_{2} \varepsilon_{p}^{c_{3}}\right)\left(1+c_{4} \ln \dot{\varepsilon}\right)$, can be fitted. If necessary, a regression curve can be also fitted to the ratios $\underline{\mu}\left(\varepsilon_{p j}, \dot{\varepsilon}\right) / \bar{\mu}\left(\varepsilon_{p j}, 1\right)$ to model the factor values $\operatorname{DIF}\left(\varepsilon_{p}, \dot{\varepsilon}\right)$ at given dynamic strain $\dot{\varepsilon}$.

\section{Conclusions}

This study presented an analysis of constitutive modelling of mechanical properties of reinforcement steel subjected to a coupled effect of dynamic loading and elevated temperatures. The analysis has been focused on the constitutive law known as the Johnson-Cook (JC) law. This law prevails in modelling the coupled effect of strain and strain rate hardening as well as thermal softening of reinforcement steels. The analysis of the JC model has led to the conclusions listed below.

1. The JC model and a series of related models are purely deterministic. Parameters of these models called material constants are determined usually by fitting the models to single stress-strain records measured for given values of strain rate and elevated temperature. Statistical variability of these records is usually ignored.

2. Information on the statistical variability of stress measured in the strain rate hardening region is very scarce. Repetitive measurements of stress-strain values in this region are usually not carried out in most experiments aimed at development of constitutive relations. The same statement is applicable to recording the stress-strain values at elevated temperatures of steel specimens. We were able to find only one article in which results of three repetitive measurements of stress values at dynamic loading are presented.

3. Currently the scarcity of data on values of stress in the hardening region does not allow to estimate the variability of these values by such dispersion measures as the coefficient of variation. However, this variability can hardly be ignored, because the stress in the hardening region is coupled with the yield stress or $0.2 \%$ offset stress and these stresses indicate a non-negligible variability.

4. The JC model can be specified for the stressstrain data in the form of small-size samples acquired in repetitive experiments. The samples can be obtained for given values of plastic strain and strain rate. Points for fitting components of the JC model can be limits of one-sided confidence intervals. These limits can be calculated by means of 
statistical procedure known as bootstrap resampling.

\section{References}

1. Cadoni, E.; Forni, D. 2021. Mechanical behaviour of B500A rebars: effect of elevated temperature and high strain-rate, Fire Safety Journal 122(103321): 1-12. https://doi.org/10.1016/j.firesaf.2021.103321.

2. Cadoni, E.; Fontana, M.; Forni, D.; Knobloch, M. 2018. High strain rates testing and constitutive modeling of B500B reinforcing steel at elevated temperatures, European Physical Journal Special Topics 227(1-2): 179199.

https://doi.org/10.1140/epjst/e2018-00046-4.

3. Forni, D.; Chiaia, B.; Cadoni, E. 2016. High strain rate response of S355 at high temperatures, Materials \& Design, 94(78): 467-478.

https://doi:10.1016/j.matdes.2015.12.160.

4. Johnson, G. R.; Cook, W.H. 1985. Fracture characteristics of three metals subjected to various strains, strain rates, temperatures and pressures, Engineering Fracture Mechanics 21(1): 31-48.

https://doi.org/10.1016/0013-7944(85)90052-9.

5. Johnson, G. R.; Cook, W. H. 1983. A constitutive model and data for metals subjected to large strains, high strain rates and high temperatures, Proceedings of the 7th International Symposium on Ballistics, Hague: International Ballistics Committee, pp. 541-547.

6. Huh, H.; Kang, W. J. 2002. Crash-worthiness assessment of thinwalled structures with the high-strength steel sheet, International Journal of Vehicle Design 30(1-2): 1-21. http://dx.doi.org/10.1504/IJVD.2002.002022.

7. Haefliger, S., Fomasi, S.; Kaufmann, W. 2021. Influence of quasi-static strain rate on the stress-strain characteristics of modern reinforcing bars, Construction and Building Materials 287(122967): 1-7.

https://doi.org/10.1016/j.conbuildmat.2021.122967.

8. Juocevicius, V.; Vaidogas, E. R. 2010. Effect of explosive loading on mechanical properties of concrete and reinforcing steel: towards developing a predictive model, Mechanika 81(1): 5-12.

9. CEB 1988. Concrete Structures under Impact and Impulsive Loading - Synthesis Report, Bulletin 187. Lausanne: Comité Euro-International du Béton. 175 p.

10. Al Salahi, A. A.; Othman, R. 2016. Constitutive equations of yield stress sensitivity to strain rate of metals: A comparative study, Journal of Engineering, Article ID 3279047: 1-7. http://10.1155/2016/3279047.

11. Scholl, N.; Minuth-Hadi, F.; Thiele, K. 2018. Modelling the strain rate dependent hardening of constructional steel using semi-empirical models, Journal of Constructional Steel Research 145(June): 414-424. https://doi.org/10.1016/j.jcsr.2018.02.013.

12. Ree, T.; Eyring, H. 1955. Theory of non-Newtonian flow. I. Solid plastic system, Journal of Applied Physics 26(7): 793-800.

http://dx.doi.org/10.1063/1.1722098.

13. Qian, H.; Yab, D.; Chen, S.; Chen, G. 2019. Effect of high temperature exposure and strain rate on mechanical properties of high-strength steel rebars, Journal of Materials in Civil Engineering 31(11): 04019261. https://doi:10.1061/(ASCE)MT.1943- 5533.0002906.
14. Zeng, X.; Wang, Z.; Huo, J. 2020a. Tensile behavior of $400 \mathrm{MPa}$-grade anti-earthquake hot-rolled ribbed bar (HRB400E) over a wide strain rate range, Construction and Building Materials 249: 118729.

https://doi.org/10.1016/j.conbuildmat.2020.118729.

15. Zeng, X.; Huo, J.; Wang, H.; Wang, Z.; Elchalakani, M. 2020. Dynamic tensile behavior of steel HRB500E reinforcing bar at low, medium, and high strain rates, Materials 13: 185: 1-15. https://doi.org/10.3390/ma13010185.

16. Forni, D.; Chiaia, B.; Cadoni, E. 2017. Blast effects on steel columns under fire conditions, Journal of Constructional Steel Research 136: 1-10. https://doi.org/10.1016/j.jcsr.2017.04.012.

17. Lin, Y. C.; Chen, X.-M.; Liu, G. 2010. A modified Johnson-Cook model for tensile behaviors of typical high-strength alloy steel, Materials Science and Engineering A 527(26): 6980-6986. https://doi:10.1016/j.msea.2010.07.061.

18. Saltelli, A.; Ratto, M.; Andres, T. 2008. Global sensitivity analysis. The Primer. Chichester: Wiley.

19. Abed, F.; Makarem, F. 2012. Comparisons of constitutive models for steel over a wide range of temperatures and strain rates, Journal of Engineering Materials and Technology 134(2): 021001 . http://10.1115/1.4006171.

20. Melchers, R. E.; Beck, A. T. 2018. Structural Reliability Analysis and Prediction. Haboken: Wiley. $506 \mathrm{p}$

21. Foster, A. S. J.; Gardner, L.; Wang, Y. 2015. Practical strain-hardening material properties for use in deformation-based structural steel design, Thin-Walled Structures 92(July): 115-129. https://doi:10.1016/j.tws.2015.02.002.

22. Marcalikova, Z.; Cajka, R. 2020. Statistical analysis of concrete reinforcement strength for analysis of reinforced concrete construction, ARPN Journal of Engineering and Applied Sciences 15(2): 225-232.

23. Cadoni, E.; Forni, D. 2020. Strain-rate effects on S690QL high strength steel under tensile loading, Journal of Constructional Steel Research 175(106348): 1-11. https://doi.org/10.1016/j.jcsr.2020.106348.

24. Ryan, T. P. 2003. Sample Size Determination and Power. Haboken: Willey. 374 p.

25. Chow, S-C.; Shao, J.; Wang, H. 2018. Sample Size Calculations in Clinical Research. $3^{\text {rd }}$ ed. Boca Raton: Chapman and Hall. 492 p.

26. Cai, Y.; Hames, D. 2010. Minimum sample size determination for generalized extreme value distribution, Communications in Statistics - Simulation and Computation 40(1): 87-98. https://doi.org/10.1080/03610918.2010.530368.

27. Gibbons, J. D.; Chakraborni, S. 2010. Nonparametric Statistical Inference, Fifth Edition. $5^{\text {th }}$ ed. Boca Raton: CRC Press. 645 p.

28. Efron, B.; Tibshirani, R. J. 1994. An Introduction to the Bootstrap. New York: Chapman \& Hall/CRC. 436 p. 


\section{E. R. Vaidogas}

\section{STATISTICAL ANALYSIS OF THE DYNAMIC PERFORMANCE OF REINFORCEMENT STEEL AT ELEVATED TEMPERATURES: THE CASE OF JOHNSON-COOK MODEL}

\section{S u m m a r y}

Description of mechanical properties of reinforcement steel by means of mathematical models known as constitutive laws is considered. The attention is focussed on the Johnson-Cook (JC) model developed to express the stressstrain relation by considering the coupled effect of strain and strain rate hardening as well as thermal softening of steel. The JC model is analysed due to its prevailing role in the practice of constitutive relation of properties of reinforcement steels. The key element of this study is a new look at the JC model from the statistical viewpoint. The JC model is subjected to examination by confronting its deterministic nature with statistical variability of experimental data that can be acquired from stress-strain records. It is stated that to now this variability has been largely ignored. The current practice of fitting the JC model to individual and non-repetitive stress-strain records is analysed. It is suggested how to address the problem of the model fitting in the case where stress-strain data is obtained by repetitive measurements. A procedure for processing small-size statistical samples extracted from this data is proposed. The essential idea of this procedure is to fit components of the JC model to limits of one-sided confidence intervals calculated by means of the statistical technique known as bootstrap resampling.

Keywords: reinforcement steel, constitutive law, JohnsonCook model, strain rate hardening, thermal softening, smallsize sample, bootstrap resampling.

Received December 17, 2021 Accepted February 04, 2022

This article is an Open Access article distributed under the terms and conditions of the Creative Commons Attribution 4.0 (CC BY 4.0) License (http://creativecommons.org/licenses/by/4.0/). 